\title{
Sustainable Development in Education of Horticulture in
}

\section{Bulgaria}

\author{
Nidal Shaban ${ }^{1}$, Sergei Bistrichanov ${ }^{1}$, Eman Kadum ${ }^{2}$ and Miroslav Tityanov ${ }^{1}$ \\ 1. University of Forestry, Sofia 1756, Bulgaria \\ 2. Agricultural Academy, Sofia 1517, Bulgaria
}

\begin{abstract}
Sustainable development in education of horticulture imposes involvement of new system in education of agricultural experts, in particular vegetable growers, such as ethical view off point to the reality of production, synthesis of traditional practices (crop rotation and mixed crops, etc.), the love to the land inherited from ancestors and modern scientific achievements from this perspective which will have a positive environmental effect over the agrarian ecosystems and the environment in general. From this perspective, lectures and practices should be based on the principles of integration of different systems and methods of production, which will include sustainable management of fertilizing and irrigation, energy use associated with production and integrated control of pests with sustainable application in the farms. These principles should be presented in a special section entitled "Sustainable Growing of Vegetables” which will form the basic knowledge related to the topic. They should be included in an appropriate place in the relevant sections for each vegetable crop, with the active participation of trained people. In order to overcome the specified problems and ensure sustainable development of the sector, it is necessary to provide well-trained people who know not only the traditional technologies used at present, but also the principles of sustainable agriculture as well, especially related with keeping natural resources to next generations.
\end{abstract}

Key words: Sustainable development, horticulture, students, training.

\section{Introduction}

The principles of sustainable development are universal and can be studied and implemented with success in agriculture, particularly in the training of people dealing with similar specific activity. According to the definition of the World Commission on Environment and Development, the viable, stable or sustainable development is such development that satisfies the needs of today's society without threating future generations of scarcity of goods for their needs [1]. The (requisitely) holistic and interdisciplinary approaches to introduce sustainable education development (ESD) in universities include: attention to achieving tangible results; involvement of local communities and the bottom-up approaches; importance of partnerships and networking; capacity building; innovation of the initiatives; attention given

Corresponding author: Nidal Shaban, professor, research field: vegetable production. to building a framework favourable to sustainable development (SD); tutoring (tutor as mediator) and values/culture/ethics/norms (VCEN) [2-5]. Such a development in the training of well-trained agricultural staff (in particular producers of vegetable products) means that it should look for a synthesis of traditional practices (crop rotation, mixed cropping, etc.) inherited from ancestors and modern achievements. Research investigation in this direction would have a positive environmental effect on both nature and agroindustry. In this connection, content of teaching material should be based on the principles of integration of different systems and production methods which include sustainable management of food, irrigation system and integrated pest control implemented in a sustainable farm. Sustainable development has been defined in many ways, but the most frequently quoted definition is "sustainable development is development that meets the needs of 
the present without compromising the ability of future generations to meet their own needs".

Sustainability is the foundation for today's leading global framework for international cooperation-the 2030 Agenda for Sustainable Development and its sustainable development goals (SDGs). In "Agenda 21 ”, ways forward in many areas, from agriculture to waste disposal, have been described. Education is a cross-cutting theme and this demonstrates how the education community has a special role to perform.

It is through education that the next generation of citizens, voters, workers, professionals and leaders will be prepared for life-long learning about sustainability $[1,6]$.

There are many higher education institutions training people for the sphere of Bulgarian agriculture in the 1990s (such as in 1987 in the Agricultural University in Plovdiv, an agro-environmental centre was opened; it became a member of IFOAM in 1993 and had as a basic task of the preparation of people and support of biologically-friendly agriculture in the country), so the introduction of environmental elements in the programs and independent disciplines related to study plans were started. A number of handbooks were published in relation to it $[7,8]$. The ecological training of agricultural producers is already a prerequisite for receiving subsidies in relation to measure 214 "agro-environmental payments" associated with the Program for Development of Rural Areas (PDRA) [9].

The analysis of the period 1997-2005 by Hadzhieva [10] showed that Bulgarian agriculture was still far from being sustainable and attention had to be paid to pollution, use of manure, soil erosion, income and productivity in the field. This finding has not lost its importance and it was established also in the National Plan for Development of Biologically-Friendly Agriculture during the period 2007-2013 [11], where the analysis on weaknesses was reported "problems related to training, education and consultancy services regarding biologically-friendly agriculture”. This means that it is very important to pay more attention to the introduction of students studying in this field to the specifics of the sphere; to analyze the current status of the problem, examine more closely the international experience and specify goals for a more successful application of sustainable development.

This paper aimed to involve SED principle to produce well-trained people who know not only the traditional technologies used at present, but also the principles of sustainable agriculture as well, especially related with keeping natural resources to next generations.

\section{Special Characteristics, Problems and Specifics of Vegetable Growing}

Fresh and processed vegetables are important and permanent part of the food of modern humans. Their consumption around the world is growing constantly. Vegetable growing is a part of the general agricultural practice, but it is a specialized activity with a number of special characteristics. The most important of these are as follows: (1) use of greenhouses for out of season growing and production of vegetables; (2) production of seedlings to avoid unfavourable condition for optimal growing of vegetable plants.

\subsection{Special Characteristics of Bulgarian Vegetable Growing}

The specifics of Bulgarian vegetable growers can be grouped as follows:

(1) Small-scale and fragmented growing with low level of specialization;

(2) Keeping the significance of family gardens, natural and semi-market farms as the main producers;

(3) Significant reduction in agricultural production volumes;

(4) Low quality and yields for produced vegetables, due to the failure to comply with agro-technical requirements on the part of agricultural producers;

(5) Higher requirements to quality and hygiene presented by importers. 


\subsection{Specifics in Bulgarian Vegetable Production and} Sale

The production of vegetables is associated with high costs and thus higher prices of final products. This brings difficulties associated with sales. There is also some negative influence presented by the direct subsidies per hectare of land, which forces agricultural producers to start growing crops with lower costs per land unit.

The characteristics of Bulgarian vegetables production and sale were as the following:

(1) Loss of traditional foreign markets, due to changed external trade situation and poor competitiveness of Bulgarian agricultural products on the international market;

(2) Real threat for Bulgarian producers to be replaced as basic suppliers of fresh produce to large supermarket chains;

(3) High prices of Bulgarian vegetables make canned products impossible to sell in the local market;

(4) Limited assortment for companies, due to the lower purchasing power of Bulgarian population and use of home-made produce;

(5) There are many problems existing during production of vegetables, such as a lack of effective organization of production activities (still have low technological level, production with high costs, high prices of seeds, mineral fertilizers, plant protection by chemical products, price of water for irrigation, absence of mechanical tools and use of human labour in relation to crops gathering, etc.); there is a low level of organization among producers (presently, there are only two authorized organizations of vegetable growers-greenhouse producers and producers of sweet pepper); there are no trade agreements between producers and traders for the sales of final products;

(6) Low prices for final products, low quality of vegetables, lack of people willing to work in agriculture and people poorly trained. These problems in combination with unfavourable climate conditions during the vegetation period for vegetables (hailstorms, heavy rains and floods, early autumn frosts, etc.) lead to on one hand, the reduced areas for vegetable growing, and on the other hand, the lower volumes in production during recent years.

\subsection{Analysis of the Vegetable Production Sector's Current Status}

The adaptation to the new competitive environment is caused by the high social and economic price, and the EU funds covered only a part of it. The benefits related to these have a limited influence due to the complex and clumsy procedures related to the provision of funds.

The field of vegetable growing was included in the common economic sphere of EU with no specific preparation. The strong competitive pressure represents a serious danger for the existence and development of the sector. In order to overcome the specified problems and ensure sustainable development of the sector, it is necessary to provide well-trained people who know not only the traditional technologies used at present, but also the principles of sustainable agriculture as well, especially related with keeping natural resources to next generations.

This imposed training of agricultural experts (in particular vegetable growers) includes the synthesis of traditional practices (crop rotation, mixed crops, etc.) with modern techniques in vegetable production, which will have a positive environmental effect over the agrarian ecosystems and the environment in general. From this perspective, lectures and practices should be based on the principles of integration of different systems and methods of production, which include sustainable management of fertilizing and irrigation; energy use associated with production; integrated control of pests with sustainable application in the farms. These principles should be presented in a special section entitled "Sustainable Growing of Vegetables” which will form the basic knowledge related to the topic. They should be 
incorporated in a suitable place in the respective sections for individual crops with active participation of trained people.

\subsection{Sustainable Management of Natural Resources in} Relation to Vegetable Growing

The successful application of these principles for sustainable development in the sector is possible after the following were realized:

(1) Analysis of climate factors in Bulgaria;

(2) Good knowledge of the genetic fund related to vegetable growing to avoid water shortage during drought;

(3) Introduction of power and water saving technologies;

(4) Lower dependence on fossil fuels and greater sustainability with regard to climate change;

(5) Consideration of social and economic aspects;

(6) Selection of plants for horticulture to suit local conditions (i.e, to reduce inputs of water, fertilizers, etc.);

(7) Promote the use of native species in landscaping;

(8) Horticultural methods to reduce inputs of water, pesticides and herbicides, peat, etc.;

(9) Composting garden waste from the community, etc..

After analysing climate factors, the agro-technical activities should be synchronized by the following:

(1) Optimization of the period for sowing and transplanting, including temperature, lighting duration, light intensity, rainfall pattern and intensity, winds, etc.;

(2) There should be specific selection of suitable soil type for vegetable farms;

(3) The natural resources should be considered, such as their volume, distribution and quality.

The modern power and water saving technologies are some of the most pressing innovations in the field of vegetable growing and they should be based on the following:
(1) Good knowledge of biological requirements of different vegetable crops;

(2) Energetic efficiency, quality and quantity of production;

(3) Protection of ground water resources;

(4) Limiting the greenhouse effects by biodegradable mulches, involvement of high techniques to reduce energy loss, modern lighting system, $\mathrm{CO}_{2}$ enrichment, and using of natural pollinators, such as bumbell bees (Bombos), etc.;

(5) Introduction of good agricultural practices, such as use of manure, rotation of crops, etc..

One of the ways for reduction of the anthropogenic pressure is the wider use of organic fertilizers. This is very much needed with regard to vegetable growing where the produce is consumed in its fresh form and processed form by consumers. The most important basis for biologically-friendly farming are the products obtained through composting, optimal sawing and transplant date, etc. [8]. The main benefits of this activity are manifested by the following:

(1) Composting is a process by which the organic materials, such as cut grass, leaves, food waste and vegetable peel, are decomposed in a way controlled by people. The obtained product (compost) is used for return of nutrients to plants, benefiting microorganisms and fertilizing the soil in farms.

(2) Composting allows limiting the volume of domestic waste which is daily directed to trash bins, at the same time, will have enhancement of soil characteristics in the farm. Humus will be formed and the structure of the soil will be enhanced.

The humanity faces a great problem, i.e., continuous reduction of water resources. Therefore, water economy, especially with regard to vegetable growing has a great significance. The successful realization of such activity is based on:

(1) Knowing biological requirements and environmental needs of plants; this is a basis for water saving;

(2) Suitably selected and regulated systems, 
depending on grown crops;

(3) Irrigation during the late afternoon when evaporation has its lowest intensity; moreover, it will reduce water cost of $50 \%$ with the same water efficiency;

(4) Mulching in order to have limited evaporation;

(5) Collection of rain water in barrels, vessels, tanks or other units;

(6) Live mulch, which is more resistant to draught when grows a little bit higher, if compared with low-cut grass;

(7) Optimization of plant distance planting will reduce water loss.

\subsection{Sustainable Vegetables Farm}

In relation to farming, different commercial products are used for protect plants, such as herbicides, fungicides and insecticides, etc.. This, however, brings permanent pollution of water, soil and final products, respectively, and it is dangerous to people health.

The provision of enough vegetables with no use of such chemicals at present is not realistic. Despite there are alternatives which can be used, the volumes will be reduced, but this will reduce the risk for consumers and the environment.

The traditional practices of vegetable growers from the past are extremely valuable asset nowadays. The farmers of the past applied agro-technical methods which, on one hand, were a tool to have compact use of land, and on the other hand, protected the crops from pests [12]. The main principle here is that prophylactics of diseases are better than treatment:

(1) The maintenance of suitable air conditions (often ventilation in the case of cabbage seedlings growing and more sparse planting in order to avoid spread of mildew (Peronospora parasitica (Pers.) Fr.);

(2) Late sowing of peas lead to reduce the percentage of seeds eaten by pests (Bruchus pisi);

(3) Suitable rotation of crops;

(4) Fencing diseased sections channel by canals, uprooting and burning of ill plants if decay was noticed on asparagus (Rhizoctonia violacea Tul. \& C. Tul.);

(5) Planting onions, garlic, basil, lavender and other similar plants can repel some insects due to the volatile compounds they release (repellents and phytoncides, etc.);

(6) Use of windbreak plants;

(7) Growing crops which benefit each other's development through vegetation, etc..

The control of pests related to the sustainable farm growing is realized through a number of practices [4]:

(1) Weeding of plants at a certain interval can bring avoidance and reduction of weeds development and spread;

(2) Use of mulching by organic and biodegradable chemicals;

(3) Use of traps for pests (pheromone and light traps, attractants, etc.);

(4) Treatment using plant chemicals (extracts) from blossoms, pine bark, some herbs or regular hoeing of the land;

(5) Use of parasites and antagonists. It is necessary to introduce integrated principles of integrated pest management in relation to the protection of vegetable produce: multi-aspect environmental approach associated with the control of pests which is coordinated with pest bio-cycles and the way they communicate with another organisms and their competitors which exist in the environment, i.e., parasites and super parasites, antagonists, etc..

Do not forget the social and economic aspects which have their influence in relation as:

(1) Maintenance of historical and cultural inheritance related to the field;

(2) Maintenance of social and economic livelihood in rural areas as a tool for the preservation of population in these areas;

(3) Relationship between producers and consumers;

(4) The role of education and increase of awareness in relation to the encouragement of sustainable horticulture development. 


\section{Conclusions}

Although there is no universal definition about what a sustainable system is, sustainable development and sustainable agriculture (including sustainable vegetable growing) should be most simply defined as one which is directed toward the economic, environmental and social sphere. The applied technologies should be financially sustainable with sufficient profit which will maintain the interest toward such a production; environmentally friendly (i.e., they should not negatively affect the existing bio-systems in the surrounding environment; they should try not only to protect this environment but also work for its maintenance and improvement). Besides, the direct producers should have a sufficient level of information, education and training in order to have proper realization of activities.

The objective reality-the membership of Bulgaria in the European Union; the constant extension of international economic, political and other links; the more intensive development of alternatives related to conventional agriculture, regardless of how it is called around the world (environmental, sustainable, biologically-friendly, etc.) put the vegetable growers in Bulgaria in a dynamic, competitive and complex environment. The natural resources and the prestige based on high quality are their important advantages. This in combination with better training and popularization in the field of sustainable vegetable growing realized in the educational institutions at different level is a basic prerequisite for future development.

The final goal set is that each of the participants in the process (producers, professors and students) should be harmoniously connected, so that they could most effectively realize their full potential in relation to new way in education of vegetable production unit according to the principles of sustainability. And then this will form a new farming culture.

\section{References}

[1] International Institute for Sustainable Development (IISD). 1990. “Sustainable Development.” Accessed April 2016. https://www.iisd.org/topic/sustainable -development.

[2] Clugston, R. 2011. "Ethical Framework for a Sustainable World: Earth Charter Plus 10 Conference and Follow Up.” J. Educ. Sustain. Dev. 5 (2): 173-6.

[3] De Leo, J. 2012. Quality Education for Sustainable Development: An Educator Handbook for Integrating Values, Knowledge, Skills and Quality Features of EDUCATION for Sustainable Development in Schooling. Adelaide, Australia: UNESCO-APNIEVE Australia Publishing.

[4] Lozano, R., Lukman, R., Lozano, F. J., Huisingh, D., and Lambrechts, W. 2013. "Declarations for Sustainability in Higher Education: Becoming Better Leaders, through Addressing the University System.” J. Clean. Prod. 48: 10-9.

[5] Education, Audiovisual \& Culture Executive Agency. 2013. Innovation in the Teaching of Sustainable Development in Life Sciences in Europe. Erasmus Networks Project.

[6] United Nations Division for Sustainable Development. 1992. “Agenda 21.” United Nations Conference on Environment \& Development Rio de Janerio, Brazil. Accessed April 2016. https://sustainabledevelopment. un.org/content/documents/Agenda21.pdf.

[7] Karov, S., Panayotov, N., and Andreev, R. 2008. Biologically-Friendly Production of Vegetables, edited by Yancheva, H. Plovdiv, Bulgaria: Vasil Aprilov.

[8] Vogtmann, H. 1990. "Environmental Farming." Environmental Agriculture Foundation, Bioselena. Accessed April 2016. http://www.bioselena.com/.

[9] Bulgarian Fund for Support of Agriculture. 2009. "Agricultural Payments from the Program for Rural Development for the Period 2007-2013.” Ordinance No. 11 of 6 April, 2009 on the Conditions of Implementation of Measure. Accessed April 2016. http://www.dfz.bg/bg/prsr-2014-2020/. (in Bulgarian)

[10] Hadzhieva, V. 2007. "Sustainable Development of Agriculture in Bulgaria.” Economic Alternative 2: 28-42.

[11] Bulgaria Ministry of Agriculture and Forestry. 2006. "National Plan for Development of Biologically-Friendly Agriculture in Bulgaria during the Period 2007-2013." Accessed April 2016. http://www.mzh.government.bg /MZH/Libraries/Organic_Farming/NOFAP_FINAL_en.sf lb.ashx.

[12] Bachvarov, S. 1986. Growing Vegetables in Bulgaria. Sofia: Zemizdat. (in Bulgarian) 